\title{
A METHOD FOR DETERMINING THE USABILITY POTENTIAL OF SHIP STEAM BOILERS
}

\author{
Lukasz Muślewski ${ }^{1}$ \\ Michał Pająk ${ }^{2}$ \\ Bogdan Landowski ${ }^{1}$ \\ Bogdan Żółtowski ${ }^{1}$ \\ ${ }^{1}$ University of Science and Technology in Bydgoszcz, Poland \\ ${ }^{2}$ University of Technology in Radom, Poland
}

\begin{abstract}
Ship large-power steam boiler may serve as an example of complex critical technical system. A basis for rational control of operation of such system is knowledge on its capability of fulfilling the tasks to which it was intended. In order to make it possible to apply computer aiding to operational decision-making the capability should be described analytically. In this paper it was proposed to express the capability of ship steam boiler (considered a complex system) to perform service tasks, by calculating components of its usability potential in a given instant $t$. To this end, was distinguished a set of steam boiler fundamental features which formulate space of its technical states. Values and characteristic intervals of the features were defined and this way sub-spaces of serviceability and non-serviceability states of the object in question were determined. Next, in the considered space, technical state of the boiler and its usability potential was determined. Owing to this it become possible to quantitatively express the steam boiler functioning capability which served as a basis for elaborating an algorithm for controlling the operational processes of a complex technical system under action. In this paper is also described a way of application of the presented method to calculation of ship steam boiler usability potential, which may be especially instrumental in the case of operational control of the boilers of the kind, equipped with interstage reheaters, i.e. those operating with high values of operational parameters.
\end{abstract}

Keywords: Ship steam boilers, operation management, complex technical systems, usability potential.

\section{INTRODUCTION}

There are two fundamental groups of processes which have place in operational phase of any technical system, hence also that of ship steam boiler, namely : operational processes and serviceability-ensuring processes called also maintenance ones. The main aim of operational use is to execute the tasks to fulfilling which a given technical system ( boiler) was built. Execution of operational use aims changes features which describe such system, as a result of action of forcing factors dependent on and independent of operation of the system [19]. If values of boiler features reach their limits then its further operation may cause failures. For this reason steam boiler is to be subjected to maintenance processes. During the maintenance processes values of boiler features are so changed as to make useful operating the boiler further possible. Changes in any boiler features force changes in its technical state, which consequently causes change in its capability of fulfilling operational tasks for which it was fitted in design and production phases. The capability is defined in the form of usability potential of steam boiler considered to be a technical system [14].

In the case of critical technical objects [22] for which occurrence of a failure is associated with high cost as well as hazard to health and life of people the problem of rational operation consists in such operational use of them as to maximize effects of its operation and prevent non-serviceability state to occur. Steam boilers (not only shipboard ones) and other main devices being a part of steam 
and machine power plants on sea-going ships, may serve as such technical objects. Additionally, both steam boilers and other technical devices operating in sea conditions cannot be subjected to renewal processes in an arbitrary instant. The instant must be therefore assigned in advance (service life strategy) and in such a way as to ensure, by ship main power subsystems, executing ship's transport tasks possible up to the assigned instant. And, the only operational strategy which makes it possible to satisfy the condition of preventing against non-serviceability state, is the state-based strategy [21]. However it does not satisfy requirements dealing with necessity of in-advance assigning the instant of qualifying a boiler or other system for renewal. Moreover, for execution of operational processes in accordance with the state-based strategy it is necessary to determine a state of the boiler in question ( considered to be a technical system ) which constitutes an important issue for all complex technical systems.

The consideration presented in this paper deals with largepower steam boilers. Boilers of the kind are presently used as main boilers on large sea-going ships, especially tankers and passenger ships $[8,10,12]$. Aspiration for increasing efficiency of boilers results in increasing their power and degree of complexity of their structure by introducing additional heating surfaces in the form of interstage reheaters. Such boilers operate at large values of steam working parameters (12MPa, $565^{\circ} \mathrm{C}-$ UTR-II Kawasaki) [2], that makes them critical technical objects.

In the case of the considered technical objects it becomes necessary to make an operational decision answering the question whether a ship may beginn its voyage or its boiler should be renewed or replaced. A basis for making such decision is determination of quantity of usability potential present in the considered technical object in a given instant.

During literature research it has been found out that accurate determination of usability potential of complex technical system meets many difficulties. The first problem is definition of the notion of usability potential itself. A detail analysis of the problem is contained in [18]. As results from the publication, to apply a new approach to the problem is necessary in order to unambiguously specify notions in the considered domain. Another research problem is association of usability potential with technical state of ship boilers. To accurately determine technical state of a boiler is not possible without its shutting down. Moreover even in the case of making diagnosis determination of some parameters of boiler elements is not possible by means of non-destructive methods. As an example may serve state of material of which steam boiler drum is built. It is common knowledge that it works under brittle fracture conditions and model of the process has not been fully so far identified that leads to necessity of performing mechanical tests on specimens taken from boiler drum. To determine usability potential of ship steam boiler in an arbitrary instant of its service it is necessary to know a model of wastage process not only of its units as it takes into account only additive features of boiler operational system, but also a model of its wastage as a technical system owing to this both additive and constitutive features of such system are taken into account. A detail analysis of usefulness of existing analytical and probabilistic models for representing changes in state of a complex technical system is given in the literature source [16]. As results from the publication, in present there is a lack of mathematical models which could make it possible to determine usability potential of complex technical systems such as ship steam boilers. Therefore, in this work is presented a way for the modelling of state of ship steam boilers considered to be technical systems as well as their usability potential, within a determined space of technical states of the systems. The described way has been next used to analyze usability potential of a selected large-power boiler considered to be a complex system.

\section{SPACE OF TECHNICAL STATES OF A SYSTEM}

For an arbitrary feature xi which describes a given system it is possible to define the variability interval $X_{i Z M}$ as a set of values which this feature may take. The variability interval is constrained by the minimum value ximin and maximum value ximax of the feature in question. Within the feature variability interval, depending on an assumed criterion for assessing value of the feature, the minimum limit value xigrmin and maximum limit value xigrmax establishing the range of permissible values, can be determined. A subset of permissible values is formed by suboptimum values contained in the interval between the minimum suboptimum value xisomin and the maximum suboptimum value xisomax. Among suboptimum values the optimum value xio can be distinguished. The above specified values and ranges are defined to be characteristic values and intervals of a feature.

It has been also defined that the set of cardinal features is the least numerous set of features considered significant for a given problem, whose instantaneous values unambiguously identify system's state [24]. The system's state described by vector of cardinal features is a point in $n$-dimensional space, where $n$ stands for power of the set of cardinal features, and the space is that of system's features.

If points of system's feature space are taken as states of the system then characteristic intervals of features which describe the system determine, in the system's feature space, $n$-dimensional hyper-fields of system's states: the field of nonpermissible states $S_{N D}$, field of permissible states $S_{D}$ and field of suboptimum states $S_{S O}$, respectively. The fields of system's features in the space of features are formulated as a cartesian product which is a common part of cylindrical extensions corresponding to relevant intervals of feature values [16].

If the set of cardinal features contains physical features of the system, for which characteristic values and intervals have been distinguished with respect to possible execution of system's service aims then in the space of system's features, are obtained hyper-fields of reliability states of the system. Such space is called the space of technical states of the system. 
For the features which are dimensions of the defined space, exactly determined, i.e. such that the interval of suboptimum values coincides with the interval of permissible values, then one obtains such split of the variability range of features that in the considered space of system's features, hyper-fields of serviceability and non-serviceability states, are formed (Fig.1) [5]. of that of life steam) then the exchanger will be considered as being in non-serviceability state [12].

It should be stressed that the conducted considerations have a detail character for relatively simple systems such as steam boilers on sea-going ships, nevertheless the presented method may be implemented also for assessing more complex technical objects or operational systems.

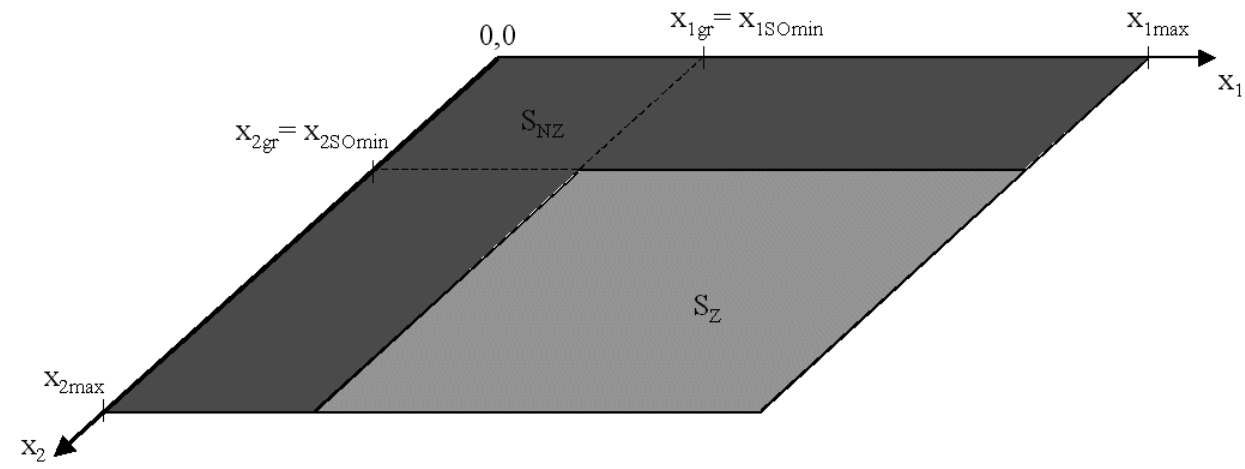

Fig. 1 - Location of fields of serviceability and non-serviceability states in the strictly determined space of technical states of an arbitrary system $R 2$

In the strictly determined space of technical states [17] a system remains in the serviceability state if values of all cardinal features are contained within their respective intervals of permissible values (1):

$s_{R}\left(x_{1}, x_{2}, \cdots, x_{n}\right) \in S_{Z} \Leftrightarrow \forall x_{i} \in X \wedge i=1,2, \cdots, n: x_{i} \in X_{D}$

where:

$s_{R}$ - real state of the system,

$x_{i}$ - i-th cardinal feature of the system,

$S_{Z}$ - hyper-field of serviceability states,

$X i D$ - interval of permissible values of $\mathrm{i}$-th feature which describes the system.

The system is in a non-serviceability state if value of at least one of the cardinal features which form the space of technical states of the system is contained within the interval of non-permissible values (2) [10]:

$s_{R}\left(x_{1}, x_{2}, \cdots, x_{n}\right) \in S_{X} \Leftrightarrow \exists X_{k} \subset X: \operatorname{card}\left(X_{k}\right) \geq 1 \wedge \forall x_{i} \in X_{k}: x_{i} \in X_{i N D}$

where:

$S_{N Z}$-hyper-field of non-serviceability states of the system.

The set of points which form the boundary of hyper-field of serviceability states is a representation of the system's limit states sgr [26].

If for the analyzed object in question, i.e. a ship steam boiler, the general coordinates used in Fig. 1, are replaced by steam pressure and temperature at outlet from heat exchanger (interstage reheater) then at assumed constant steam load, constant inlet steam parameters as well as constant amount of heat in exhaust gas, one obtains the space of reliability states of the considered exchanger. If values of outlet steam parameters drop below the determined ones (usually, temperature equal to that of life steam, $5 \mathrm{~K}$, and pressure reduced below a half

\section{USABILITY POTENTIAL AND ITS CHANGES OCCURRING IN OPERATIONAL PHASE}

In the considered space the system's real state $s_{R}$ is represented in the form of a point of coordinates equal to instantaneous values of its cardinal features. Quantity of usability potential contained in the system is function of its technical state. Therefore it was assumed that the usability potential contained in the system is a vector with its origin placed in the origin of the coordinate frame and the end in the point which represents the system's real state $s_{R}$. Quantity of the usability potential contained in the system is equivalent to length of the vector (3) [4]:

$$
\operatorname{Pu}\left(s_{R}\right)=\sqrt{\sum_{i=1}^{n}\left(x_{R i}\right)^{2}}
$$

where:

$P u\left(s_{R}\right)$ in the system in the state $s_{R}$.

The vector whose origin is placed in the point belonging to the boundary of the hyper-field of serviceability states and the end in the point representing system's real state, is interpreted to be the usability potential of quantity possible to be transformed as a result of operation of the system, contained in the system in a given instant $t$. The quantity was calculated as the vector length (4) [18]:

$$
\delta P u=\left\{\begin{array}{l}
0 \wedge s_{R} \in S_{N Z} \\
\sqrt{\sum_{i=1}^{n}\left(x_{R i}-x_{B N Z D i}\right)^{2}} \wedge s_{R} \in S_{Z}
\end{array}\right.
$$


where:

$\delta P u$ - available quantity of usability potential,

$x_{R i}$ - value of $i$-th feature of real state of the system,

$x_{B N Z D i}$ - value of $i$-th feature of system's state represented by a point which belongs to the boundary of the hyper-field of serviceability states,

$S_{N Z}$ - hyper-field of non-serviceability states,

$S_{Z}$ - hyper-field of serviceability states.

During conducting operational processes technical object is subjected to action of forcing factors both dependent upon and independent of functioning the object. The action of forcing factors onto technical object introduces changes in values of its cardinal features [15]. As technical state of the system is represented in the form of a point of coordinates equal to instantaneous values of cardinal features then the process of changes in system's states may be presented in the form of a trajectory whose every point represents system's state in the instant $t, t \subset\left[t_{1}, t_{2}\right]$ [20]. By determining the quantity of usability potential contained in the system (3), for the beginning point of the trajectory, $s_{1}=s\left(t_{1}\right)$, and the end point of the trajectory, $s_{2}=s\left(t_{2}\right)$, one can calculate the change in quantity of usability potential, which occurs during realization of the considered operational process, as the length of the vector of change in usability potential (5)

$$
\Delta P u=|\overrightarrow{\Delta P u}|: \overrightarrow{\Delta P u}=\overrightarrow{\Delta P u}\left(s_{1}\right)-\overrightarrow{\Delta P u}\left(s_{2}\right)
$$

By assuming the selected limit state sgr as a point with respect to whom quantity of available usability potential is determined, one is able to determine the quantity for the beginning point and end point of the analyzed trajectory. Difference of the determined vectors for the beginning point and end point is the vector of change in quantity of available usability potential of the system, and its length is the change in the quantity, $\Delta \delta P u(6)$ :

$$
\Delta \delta P u=|\overrightarrow{\Delta \delta P u}|: \overrightarrow{\Delta \delta P u}=\overrightarrow{\delta P u}\left(s_{1}\right)-\overrightarrow{\delta P u}\left(s_{1}\right)
$$

where:

$\Delta \delta P u$ - change in quantity of available usability potential.
It should be noticed that for the points not belonging to the hyper-field of non-serviceability states the usability potential vector is a sum of usability potential vector of the selected limit state sgr and the available quantity of usability potential determined with respect to the selected limit state described by the relation (7) and illustrated in Fig. 2.

$$
\forall s_{R} \notin S_{N Z}: \overrightarrow{P u}\left(s_{R}\right)=\overrightarrow{P u}\left(s_{g r}\right)+\overrightarrow{\delta P u}\left(s_{R}\right)
$$

As the sum is constant for a determined real state, hence by selecting (for the calculations) such limit state for which quantity of usability potential is the least, the largest quantity of available usability potential is obtained. Such state is determined to be the optimum limit state.

\section{ANALYSIS OF CHANGES IN USABILITY POTENTIAL OF A SELECTED SUBSYSTEM OF FLOATING UNIT}

During conducting the investigations, a large-power steam boiler system fitted with interstage reheater, used on a selected floating unit, was analyzed. Such object is a critical technical object hence one of the most important aims of its service is not to permit a non-serviceability state to occur, that is in line with the main aim of ship service [9]. However, because of complex structure and multi-dimensional relations between elements of the system in question, to describe numerically the discussed service aim is really very difficult.

Prevention against occurrence of a non-serviceability state requires to determine an available quantity of usability potential contained in a crucial (from the point of view of operation) element, subsystem or complex system, in a given instant $t$. Hence, to make the investigations complete it is necessary to determine technical state of the boiler. The technical state results from technical state of particular boiler subsystems, including boilers, shafts and steam turbines themselves, but taken as a state of multi-dimensional complex technical system, it does not result directly from them. Simultaneously, state of particular elements is not monitored in a continuous way.

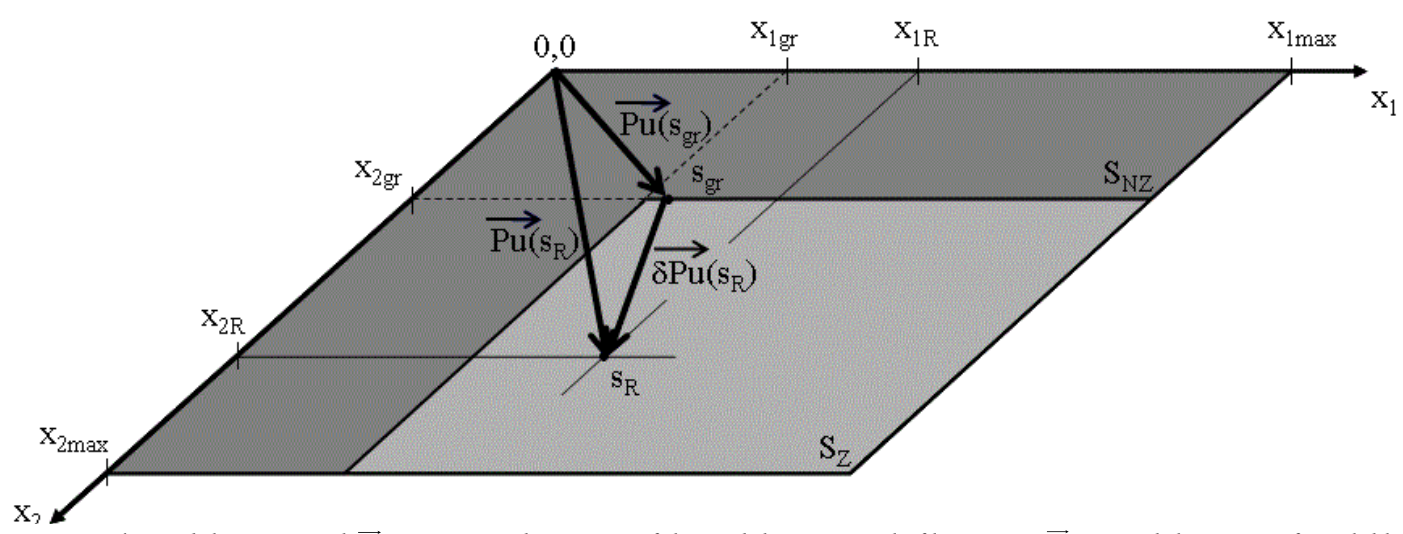

Fig.2 - The usability potential $\overrightarrow{P u}\left(s_{R}\right)$ expressed as a sum of the usability potential of limit state $\overrightarrow{P u}\left(s_{g r}\right)$ and the vector of available quantity of usability potential $\overrightarrow{\delta P u}\left(s_{R}\right)$ in the space of technical states of an arbitrary system, $R^{2}$. 
State of boiler proper piping or reheaters and heaters as well as a degree of their scaling is not directly monitored but it can be only determined by measuring values of outlet steam parameters. Simultaneously, any measurement of the kind, e.g. steam pressure at outlet from the boiler, is influenced by many elements of steam-water circuit of the boiler, which, in conditions of varying steam load, is very important but particularly difficult to be verified. Thus, the first issue is to numerically determine technical state of particular elements of the boiler. In addition, interrelations between boiler elements make accurate determining the whole system not possible even if state of its particular elements is known. Since it is hard to find cause of a drop in temperature of superheated steam despite the same amount of combusted fuel. Because it may be a problem connected with fuel quality, technical state of burners, state of boiler proper piping, reheater or quality of combustion process. It seems therefore that the most rational approach is to consider the boiler to be a power machine and relate its technical state expressed indirectly by efficiency of transformation of fuel chemical energy into thermal energy of outlet steam, to amount of energy consumed in operational process $[1,3,6,7,11,23,25]$.

Taking the above given conclusion into account, the way of description of system's technical state presented in this work, was applied to solving the problem. The features simultaneously describe quality of system's operation [13]. For this reason was performed identification of cardinal features which form dimensions of the space of technical states, within the set of deviations enumerated in TKE? method of operational quality control of steam boiler system. The method is commonly used for assessment of operational quality of devices of power units [15]. In these considerations the method was applied to analyzing quality of steam boiler operation.

As a result of the performed analyses were selected the deviations directly associated with boiler operation quality, namely:

- $q 3$ - deviation (dealing with heat consumption per $1 \mathrm{kWh}$, determined on the basis of temperature of interstage superheated steam $[\mathrm{kJ} / \mathrm{kWh}]$ ),

- $q 4$ - deviation ( dealing with heat consumption per $1 \mathrm{kWh}$, determined on the basis of steam throttling in the interstage reheater $[\mathrm{kJ} / \mathrm{kWh}]$ ),

- $q 5$ - deviation (dealing with heat consumption per $1 \mathrm{kWh}$, determined on the basis of injection of water into interstage superheated steam $[\mathrm{kJ} / \mathrm{kWh}])$ and

- $q 8$ - deviation (dealing with heat consumption per $1 \mathrm{kWh}$, determined on the basis of decreased efficiency of the boiler $[\mathrm{kJ} / \mathrm{kWh}])$

- all are considered to be cardinal features which determine the space of technical states of the boiler in question. Moreover, it was assumed that - from the point of view of technical state of the system - the interval of permissible values for the distinguished features coincides with that for suboptimum values, which means that the features are strictly determined.
On the basis of measurement results obtained from tests of a steam boiler installed on an existing ship, instantaneous values of particular selected deviations were calculated and functional relationships of the particular deviation values in function of time were next obtained by using multinomial approximation. For each of the achieved approximation multinomial value of derivative was calculated within its determination interval. On this basis it was stated that each of the multinomials is a constantly increasing function. This proves the assumption that values of cardinal features of the investigated operational system, which determine the space of its technical states in operational process, should vary in a strictly monotonous way. For each of the multinomials, minimum and maximum value was also calculated, which, together with the strictly increasing character of the runs, defines their values at the beginning and end of the determination interval. On this basis was proved the assumption that values of the analyzed deviations decrease in steps as a result of performed serviceability assurance processes. In means that all the assumed cardinal features of ship boiler operational system are renewal-dependent in the serviceability assurance process.

Next, fields of serviceability and non-serviceability states of boiler system were defined in the space of its features, which are described by limit values of the system's features. In the case of the considered system the space of features is described by the deviations : $q 3, q 4, q 5, q 8$. For the analysis are appropriate the values of the deviations corresponding to boiler operation at a given speed of the ship, as only then the interstage reheater is under operation. Therefore periods of boiler operation during port manoeuvres or ship going under reduced speed should be excluded from the analysis.

During the tests in service, limit values of the deviations were determined to be maximum ones which occur in the end of boiler operation periods just before passing it to renewal. The values are interpreted to be the biggest at which there is no hazard of occurrence of a non-serviceability state ( $0 \%)$. Simultaneously, minimum values of the deviations recorded in the beginning of before-repair periods, were taken the smallest.

Tab. 1 - Characteristic values of the deviations

\begin{tabular}{|c|c|c|c|c|}
\hline Deviation & $\begin{array}{c}\text { Smallest } \\
\text { value before } \\
\text { repair }[\mathrm{kJ} / \\
\mathrm{kWh}]\end{array}$ & $\begin{array}{c}\text { Biggest } \\
\text { value before } \\
\text { repair } \\
{[\mathrm{kJ} / \mathrm{kWh}]}\end{array}$ & $\begin{array}{c}\text { Smallest } \\
\text { value after } \\
\text { transposition } \\
{[\mathrm{kJ} / \mathrm{kWh}]-} \\
\text { minimum } \\
\text { limit value of } \\
\text { non-permissible } \\
\text { value interval } \\
\mathrm{D}\end{array}$ & $\begin{array}{c}\text { Biggest } \\
\text { value after } \\
\text { transposition } \\
{[\mathrm{kJ} / \mathrm{kWh}]-} \\
\text { maximum } \\
\text { limit value of } \\
\text { non-permissible } \\
\text { value interval } \\
\mathrm{E}\end{array}$ \\
\hline$q 3$ & -43.78 & 16.88 & 0 & 0 \\
\hline$q 4$ & -27.95 & 41.13 & 0 & 69.66 \\
\hline$q 5$ & -22.63 & 31.94 & 0 & 54.57 \\
\hline$q 8$ & -45.76 & 98.92 & 0 & 144.68 \\
\hline
\end{tabular}

In order to obtain split of the variability range of features of the boiler considered to be a system, appropriate for strictly 
determined space of technical states, transposition of the coordinate frame was performed. This way the hyper-field of non-serviceability states (Col. D and E, Tab.1) as well as the coordinates of optimum limit point (Col. E, Tab. 1), were determined.

On the basis of the determined coordinates of the hyperfields of serviceability and non-serviceability states it is possible to analyze degree of use of available usability potential of ship boiler after every completed transport task. In Tab. 2 , values of usability potential quantity in the beginning of transport task and the end of it, as well as values of changes in the available quantity, are presented for exemplary transport tasks.

Tab. 2 - Changes in available usability potential - operational processes

\begin{tabular}{|c|c|c|c|}
\hline No. & $\begin{array}{c}\text { Available quantity } \\
\text { of usability potential } \\
\text { in the beginning of } \\
\text { operational period }\end{array}$ & $\begin{array}{c}\text { Available quantity } \\
\text { of usability } \\
\text { potential in the } \\
\text { end of operational } \\
\text { period }\end{array}$ & $\begin{array}{c}\text { Change in } \\
\text { available } \\
\text { usability } \\
\text { potential }\end{array}$ \\
\hline- & {$[\mathrm{kJ} / \mathrm{kWh}]$} & {$[\mathrm{kJ} / \mathrm{kWh}]$} & {$[\mathrm{kJ} / \mathrm{kWh}]$} \\
\hline 1. & 767.25 & 391.71 & 375.54 \\
\hline 2. & 525.46 & 54.29 & 471.17 \\
\hline 3. & 820.28 & 468.75 & 351.53 \\
\hline 4. & 467.81 & 70.89 & 396.92 \\
\hline 5. & 326.16 & 13.96 & 312.20 \\
\hline 6. & 736.89 & 325.21 & 411.68 \\
\hline & \multicolumn{3}{|c|}{ Mean value } \\
\hline
\end{tabular}

Comparing available quantities of usability potential of the boiler, which remain after completion of every transport task, and mean value of change in available usability potential, which results from fulfilment of the tasks by the ship, one is able to determine whether the remaining quantity of usability potential is sufficient for undertaking a subsequent transport task. Basing on the data presented in Tab. 2, one can plan further carrying out transport tasks in the cases represented by the data given in Row 1 and 3 of the table.

\section{SUMMARY}

Operational management of ship steam boilers representing complex technical objects, requires, because of degree of their complicity and multi-dimensional relationships between their components, to implement an approach based on general theory of systems. Such approach is especially favourable in the case of the so critical objects operating in sea conditions as ship steam boilers which are subjected to special limitations as to the carrying out of operational processes and ensuring of their serviceability. In this work is presented a system method of description of usability potential and its changes in the space of technical states of an arbitrary system. The method was applied to analyzing usability potential of a steam boiler operating on an existing ship and its changes occurring in operational processes of the considered object of investigations. Consequently, the space of technical states of an arbitrary boiler was formulated together with its hyper-fields of serviceability and non-serviceability states, as well as the optimum limit point, quantities of available usability potential and its changes which occurs during execution of transport tasks, were also determined. On this basis, premises were reached for deciding on whether to pass the object to maintenance operations or to conduct its use further. The proposed method is a unique approach to the issue of determination of usability potential of complex technical objects, which makes it possible to take into account system relationships in modelling operational processes. Application of the method to determination of usability potential of ship large-power steam boilers makes it possible to perform analysis of operational state of the boiler analytically, owing to this one can strictly calculate whether a given propulsion unit will be able to reliably carry out a subsequent operational task or it should be subjected to maintenance operations. Such decision-making is an important issue in the case of sea-going ships where any failures and necessary repairs during voyage seriously endanger their safety and serviceability as well as constitute source of possible financial losses.

Further planned research will be aimed at the representing of relationships of change in available usability potential of the boiler in function of the conditions in which shipping tasks are conducted, i.e. sea conditions, ship service speed and quantity and rate of changes in boiler load.

\section{BIBLIOGRAPHY}

1. Balcerski A.: Ship power plants. Fundamentals of thermodynamics, engines and main propulsions, auxiliary devices, installations ( in Polish). Gdansk University of Technology, Gdańsk 1990

2. Bucknall R.W.G., Attah E. E.: Energy use onboard LNG steam ships. Proceedings of the Low Carbon Shipping Conference, London 2013

3. Charchalis A., Krefft J.: Main dimensions selection methodology of the container vessels in a preliminary stage, KONES, Journal of Power train and Transport, 2009, Vol. 16, No. 2

4. Dorst L., Fontijne D., Mann S.: Geometric algebra for computer science. Elsevier 2007

5. Downarowicz O.: Operation systems. Management of engineering resources. in Polish). Instytut Technologii Eksploatacji ( Institute of Operation Technology), Radom 2005

6. Gardzilewicz A., Obrzut D., Szymaniak M.: Polish aspects in the modern design solutions of steam turbine flow systems. Polish Maritime Research, Special issue 2009/S1

7. Grządziela A., Musiał J., Muślewski Ł., Pająk M.: A method for identification of non-coaxiality in engine shaft lines of a selected type of naval ships. Polish Maritime Research. 
Vol. 22 No. 1(85), 2015

8. Górski Z., Perepeczko A.: Ship steam boilers (in Polish). Gdynia Maritime University, Gdynia 2013

9. Górski W., Burciu Z.: Identification of main parameters which impact fuel consumption on ships in real operational conditions ( in Polish). Logistyka 4/2011, Poznań 2011

10. Harrington R.L.: Marine Engineering : ...? The Society of Naval Architects and Marine Engineers, New York 1971

11. Samsung Heavy Industry : Machinery operating manual, 300000 DWT Crude Oil Tanker. Publ. Samsung HI Co., South Korea, October 2000.

12. Molland A.F.: The Maritime Engineering Reference Book, A Guide to Ship Design, Construction and Operation. Butterworth 2013

13. Muślewski Ł.: Evaluation Method of Transport Systems Operation Quality. Polish Journal of Environmental Studies. Vol. 18, No. 2A, Hard ? Olsztyn 2009

14. Oziemski S.: Man in machine (in Polish). Instytut Technologii Eksploatacji (Institute of Operation Technology), Radom 2004

15. Pająk M.: Fuzzy extension of TKE method for determining operation process quality of power units (in Polish). Zagadnienia Eksploatacji Maszyn 4/2007, Instytut Technologii Eksploatacji ( Institute of Operation Technology), Radom 2007

16. Pająk M.: The Analysis of Usefulness of Operational Potential Consumption Models to Control Complex Technical Systems Maintenance. Journal of KONES Power train and Transport vol. 17 No. 2, Warsaw 2010

17. Pająk M.: The technical states' space in the modelling process of operation tasks of a complex technical system. Maintenance Problems 1/2014, Instytut Technologii Eksploatacji ( Institute of Operation Technology), Radom 2014

18. Pająk M.: Operational potential of a complex technical system. Maintenance Problems 4/2015, Instytut Technologii Eksploatacji ( Institute of Operation Technology), Radom 2015

19. Pająk M., Muślewski Ł.: Fuzzy model for assessment of operation quality control of complex operational system (in Polish). Problemy Eksploatacji 3/2005, Instytut Technologii Eksploatacji ( Institute of Operation Technology), Radom 2005

20. Pająk M., Muślewski Ł.: Computerisation of systems operation quality assessment. 10th International Conference on Computer Systems' Aided Science, Industry and Transport - Transcomp, Zakopane 2006

21. Pająk M., Woropay M.: Maintenance strategy by controlled consumption of operational potential. Journal of KONES Power train and Transport vol. 16 No. 4, Warsaw 2009

22. Pihowicz W.: Technical safety engineering. Fundamental problems ( in Polish), WNT ( Technical Scientific Publishers) Warsaw 2008

23. Rodríguez C., Antelo F., De Miguel A., Carbia J.: Study of possibilities of using a steam plant type "reheat" and mixed boilers of coal and fuel-oil for the propulsion of bulk carriers. Journal of Maritime Research, Vol. VIII. No. 2, Santander 2011

24. Woropay M., Muślewski Ł.: Quality in system formulation ( in Polish). Instytut Technologii Eksploatacji ( Institute of Operation Technology), Radom 2005

25. Yi Y-S., Watanabe Y., Kondo T., Kimura H., Sato M.: Oxidation Rate of Advanced Heat-Resistant Steels for Ultra-Supercritical Boilers in Pressurized Superheated Steam. Journal of Pressure Vessel Technology, Vol. 123, 2001

26. Zdoński M., McGeough J.A., Szpytko J.: On the use of maintenance developments to improve inherent reliability. Engineering achievements across the global village. International Journal of INGENIUM, Cracow - Glasgow 2005

\section{CONTACT WITH THE AUTHOR}

\author{
Łukasz Muślewski \\ e-mail:l.muslewski@wp.pl \\ University of Science and Technology in Bydgoszcz \\ Al. Prof. S. Kaliskiego 7 \\ 85-796 Bydgoszcz
}

Poland 